\title{
Lymphatic filariasis transmission in Rufiji District, southeastern Tanzania: infection status of the human population and mosquito vectors after twelve rounds of mass drug administration
}

\author{
Clarer Jones ${ }^{1 *}$, Billy Ngasala ${ }^{1,2}$, Yahya A. Derua ${ }^{3}$, Donath Tarimo ${ }^{1}$, Lisa Reimer ${ }^{4}$, Moses Bockarie ${ }^{5}$
} and Mwelecele N. Malecela ${ }^{6}$

\begin{abstract}
Background: Control of lymphatic filariasis (LF) in most of the sub-Saharan African countries is based on annual mass drug administration (MDA) using a combination of ivermectin and albendazole. Monitoring the impact of this intervention is crucial for measuring the success of the LF elimination programmes. This study assessed the status of LF infection in Rufiji district, southeastern Tanzania after twelve rounds of MDA.

Methods: Community members aged between 10 and 79 years were examined for Wuchereria bancrofti circulating filarial antigens (CFA) using immunochromatographic test cards (ICTs) and antigen-positive individuals were screened for microfilaraemia. All study participants were examined for clinical manifestation of LF and interviewed for drug uptake during MDA rounds. Filarial mosquito vectors were collected indoor and outdoor and examined for infection with $W$. bancrofti using a microscope and quantitative real-time polymerase chain reaction (qPCR) techniques.
\end{abstract}

Results: Out of 854 participants tested, nine (1.1\%) were positive for CFA and one (0.1\%) was found to be microfilaraemic. The prevalence of hydrocele and elephantiasis was $4.8 \%$ and $2.9 \%$, respectively. Surveyed drug uptake rates were high, with $70.5 \%$ of the respondents reporting having swallowed the drugs in the 2014 MDA round (about seven months before this study). Further, $82.7 \%$ of the respondents reported having swallowed the drugs at least once since the inception of MDA programme in 2000. Of the 1054 filarial vectors caught indoors and dissected to detect $W$. bancrofti infection none was found to be infected. Moreover, analysis by qPCR of 1092 pools of gravid Culex quinquefasciatus collected outdoors resulted in an estimated infection rate of $0.1 \%$. None of the filarial vectors tested with qPCR were found to be infective.

Conclusion: Analysis of indices of LF infection in the human population and filarial mosquito vectors indicated a substantial decline in the prevalence of LF and other transmission indices, suggesting that local transmission was extremely low if occurring at all in the study areas. We, therefore, recommend a formal transmission assessment survey (TAS) to be conducted in the study areas to make an informed decision on whether Rufiji District satisfied WHO criteria for stopping MDA.

Keywords: Lymphatic filariasis, Mass drug administration, Microfilaremia, Circulating filarial antigens, Hydrocele, Elephantiasis, Wuchereria bancrofti, Tanzania

\footnotetext{
* Correspondence: clarajones2003@yahoo.co.uk

${ }^{1}$ Department of Parasitology and Medical Entomology, Muhimbili University

of Health and Allied Sciences, P. O. Box 65011, Dar es Salaam, Tanzania

Full list of author information is available at the end of the article
}

(c) The Author(s). 2018 Open Access This article is distributed under the terms of the Creative Commons Attribution 4.0 International License (http://creativecommons.org/licenses/by/4.0/), which permits unrestricted use, distribution, and reproduction in any medium, provided you give appropriate credit to the original author(s) and the source, provide a link to the Creative Commons license, and indicate if changes were made. The Creative Commons Public Domain Dedication waiver (http://creativecommons.org/publicdomain/zero/1.0/) applies to the data made available in this article, unless otherwise stated. 


\section{Background}

Lymphatic filariasis (LF) is the second most common vector-borne parasitic disease after malaria and is found in over 83 tropical and subtropical countries [1]. It is estimated that one billion people are at risk of infection and 120 million are affected by LF. Of those at risk of infection, 65\% reside in the Southeast Asia, 30\% in Africa, and the remainder live in other parts of the tropical world [2, 3]. In sub-Saharan Africa, LF is caused by infection with the parasitic nematode Wuchereria bancrofti and transmitted by night-biting mosquitoes of the genera Anopheles and Culex [4]. The most important filarial vectors in sub-Saharan Africa are Culex quinquefasciatus (widespread in urban and semi-urban areas) and members of the Anopheles gambiae complex and An. funestus group found in rural areas [5].

In 1997, the World Health Assembly passed a resolution calling for the elimination of LF as a public health problem globally $[6,7]$. As a result, the Global Programme to Eliminate Lymphatic Filariasis (GPELF) was launched in 2000 by the World Health Organization (WHO). The programme had a principle objective of interrupting the transmission of W. bancrofti and Brugia malayi through the application of annual mass drug administration (MDA) to the entire at-risk population as well as management and prevention of LF-related disabilities [8]. The fundamental assumption behind the MDA approach is that once the community has been treated long enough, levels of microfilariae will remain below that required to sustain transmission [9]. It has been suggested that after four to six consecutive rounds of MDA, microfilariae load in the endemic population is expected to fall below $1 \%$, and this reduction in microfilaraemia will lead to the reduced acquisition of new infections [10].

LF is endemic in many parts of mainland Tanzania where nearly $70 \%$ of the population is at risk, and six million people are estimated to have disabilities due to the disease [11]. LF endemicity varies across the country, with high antigenemia levels of $45-60 \%$ along the coast to $2-4 \%$ in western Tanzania [11]. Tanzania was one of the first countries in sub-Saharan Africa to adopt the WHO recommended strategy of applying annual MDA to eliminate LF, and the Tanzanian National Lymphatic Filariasis Elimination Programme (NLFEP) was launched on Mafia Island in 2000 [12]. Since then, the programme has expanded to cover a total population of 13 million people treated at least once with ivermectin and albendazole, with a target to extend the coverage to the entire estimated at-risk population of around 34 million people [11].

Monitoring of the transmission dynamics during MDA implementation is essential for measuring the progress and defining MDA endpoints. The main measures used to assess the impact of LF MDA have relied upon detection of parasites, parasite antigens, parasite DNA and/or anti-parasite antibodies in humans [13]. However, detecting these indicators of LF infection in humans are not always definitive of local transmission as they may not account for immigration of infected individuals to areas where transmission has been controlled [13]. On the other hand, detection of filarial parasites in mosquito vectors indicates infection uptake from human hosts while the presence of infective third-stage larvae (L3) indicates a possibility of local transmission [14, 15]. Thus, monitoring W. bancrofti infection in humans together with vector infectivity provides a more sensitive measure of local transmission. The present study monitored $W$. bancrofti infection status of the human population and mosquito vectors after twelve annual rounds of MDA with a combination of ivermectin (150-200 $\mathrm{mg} / \mathrm{kg}$ ) and albendazole (400 mg) delivered to individuals aged five years and above in the highly endemic area of southeastern Tanzania.

\section{Methods \\ Study area}

This study was conducted in Rufiji District $\left(7^{\circ} 57^{\prime} \mathrm{S}, 38^{\circ}\right.$ 43'E) southeastern Tanzania about $150 \mathrm{~km}$ south of Dar es Salaam. Based on 2012 census data, the district had a total population of 217,274 people [16]. The district lies within the floodplain of Rufiji River, c.500 m above sea level. The district has two main rain seasons; a long rainy season between February and May and a shorter less intense one from October to December. The annual rainfall ranges between $800-1000 \mathrm{~mm}$. Rufiji District was purposively selected for the study due to its history of high LF prevalence before the start of elimination activities based on ivermectin and albendazole MDA in 2002. Twelve rounds of annual MDA were completed in Rufiji District between 2002 and 2014 (Table 1).

The district has a total of 83 registered villages across 19 administrative wards. Using stratified random sampling, five villages (Bungu, Nyambili, Nyanjati, Mchukwi and Nyamisati) were selected for the study representing three main ecological settings of the district. Nyamisati is located along the coast of the Indian Ocean while both Bungu and Nyanjati are inland villages with high and low population, respectively. Nyambili is a lowland village at the basin of Rufiji River prone to flooding during the rainy season, and Mchukwi is a relatively highland village. Before MDA in 2000, the prevalence of W. bancrofti circulating filarial antigens (detected using immunochromatographic test (ICT) cards), microfilaraemia, hydrocele, and elephantiasis were 49, 18, 12 and 4\%, respectively (Tanzanian Ministry of Health and Social Welfare (MoHSW) 2000, unpublished). The present study was conducted in April 2015, about seven months after the 12th annual round of MDA based 
Table 1 Reported treatment coverage during ivermectin and albendazole MDA intervention in Rufiji District, southeastern Tanzania

\begin{tabular}{llll}
\hline MDA No. & Treatment year & Target population & $\begin{array}{l}\text { Treated population } \\
\text { (\% coverage) }\end{array}$ \\
\hline 1 & 2002 & 138,370 & $75,135(54.3)$ \\
2 & 2003 & 141,628 & $123,216(87.0)$ \\
3 & 2004 & 144,962 & $136,267(94.0)$ \\
4 & $2005^{a}$ & - & - \\
5 & 2006 & 151,868 & $85,046(56.0)$ \\
6 & 2007 & 155,443 & $116,583(75.0)$ \\
7 & 2008 & 159,103 & $115,350(72.5)$ \\
8 & 2009 & 162,848 & $130,279(80.0)$ \\
9 & 2010 & 166,682 & $113,677(68.2)$ \\
10 & 2011 & 170,606 & $150,133(88.0)$ \\
11 & 2012 & 236,614 & $146,060(61.7)$ \\
12 & 2013 & 243,835 & $149,163(61.2)$ \\
\hline
\end{tabular}

${ }^{\mathrm{a} M D A}$ was not implemented in 2005

on a combination of ivermectin and albendazole delivered in September 2014.

\section{Study population and sampling}

Study participants were selected from a list of names of heads of households obtained from the respective village executive officers. Forty heads of households were randomly selected from the list, and all members of the household included for the survey. In 2012, the average household size in Rufiji was reported to be five individuals [16], and thus it was estimated to screen 200 individuals from each village. On the survey date, participants were invited to a central place (dispensary or school premises) for blood testing and interviews. Participants who did not turn up for screening in the central place were followed at their homes.

\section{LF prevalence, burden and MDA compliance}

Consented community members aged between 10 and 79 years) in the study villages were examined for $W$. bancrofti CFA using immunochromatographic test (ICT) cards (Binax Now ${ }^{\oplus}$ Filariasis, Inverness Medical Innovations Inc., Massachusetts, USA) following the manufacturer's instructions. Briefly, $100 \mu \mathrm{l}$ of finger-prick blood was collected from each participant and applied to the test card. Test results were read after precisely $10 \mathrm{~min}$ as positive, negative or undetermined. All CFA positive cases detected during the daytime were further examined for microfilaria (MF) by using counting chamber technique [17]. For MF testing, $100 \mu \mathrm{l}$ of finger-prick blood was collected with sterile heparinised capillary tubes starting from 22:00 to 00:00 h and transferred to sample tubes with $900 \mu \mathrm{l}$ of $3 \%$ acetic acid. In the laboratory, the samples were transferred into the counting chamber and examined for MF under a compound microscope. Moreover, participants were examined in privacy by the study clinicians for clinical manifestation of LF. Using pre-designed forms, demographic information such as sex, age, marital status, occupation, and duration of residence in Rufiji were recorded for all participants. Moreover, participants were interviewed on whether they had swallowed ivermectin and albendazole distributed in the community in September 2014 and also their participation in drug uptake in any of the previous 12 annual MDA campaigns.

\section{Vector and transmission surveys}

Filarial mosquito vectors were collected from 10 selected houses from each village using Centre for Disease Control (CDC) light traps (John W. Hock Company, Gainesville, USA). To optimize trap yield, households with thatched roof and open eaves were selected from different parts of each of the trapping village in a non-random approach. Sleeping rooms with a bed and a willing occupant was selected for trapping. CDC light trap was placed beside an occupied bed (with occupant protected with a long-lasting insecticide-treated net) in each household for two consecutive nights. Light traps were switched on between 17:00 and 18:00 $\mathrm{h}$ and then turned off between 06:00 and 07:00 $\mathrm{h}$ the following morning. Mosquitoes collected from each light trap type were transferred separately into labeled paper cups covered with a netting material and offered cotton pads soaked in a $10 \%$ glucose solution and transported to the field laboratory. In the laboratory, they were knocked down with chloroform, sorted, and then identified based on morphological characters. Freshly-killed female filarial mosquito vectors were dissected and examined under a microscope for parity and infection with $W$. bancrofti as described previously [18].

CDC gravid traps were also set outdoors (in the same households used for setting a light trap) to collect gravid mosquitoes for two consecutive nights in each house. The traps were set in peri-domestic areas, and the trappings were conducted as described by Irish et al. [19]. In brief, the traps were switched on between 17:00 and 18:00 $\mathrm{h}$ and switched off the next morning between 06:00 and 7:00 h. Collected mosquitoes were treated as described for light trap catch except that the filarial vectors from gravid traps were preserved individually in Eppendorf tubes containing silica gel desiccants for later detection of infection using the quantitative real-time polymerase chain reaction (qPCR) technique.

For qPCR processing, gravid $C x$. quinquefasciatus were dissected to separate head, thorax, and abdomen. Combined thorax and abdomen segments were processed separately from the heads in pools of five mosquitoes. DNA was extracted from pooled mosquito segments by using the Livak method [20]. In brief, mosquitoes were 
homogenized in Livak buffer $(0.5 \%$ sodium dodecyl sulphate (SDS), $0.08 \mathrm{M}$ sodium chloride $(\mathrm{NaCl}), 0.16 \mathrm{M}$ sucrose, $0.5 \mathrm{M}$ ethylenediaminetetraacetic acid (EDTA) and $0.12 \mathrm{M}$ Tris- $\mathrm{HCl}$ ), proteins and debris separated with $8 \mathrm{M}$ potassium acetate, and DNA precipitated with ethanol. The resultant DNA was rinsed in 70\% cold ethanol, dried and re-suspended in tris-acetate-EDTA (TAE) buffer. An aliquot of extracted DNA from heads was combined with those from the thorax and abdomen segments and screened in the initial qPCR run to detect infection with W. bancrofti. After that, the heads of the positive pools were re-tested in the follow-up qPCR screening to establish whether the positive signal from the initial qPCR run was obtained from the head segment.

The extracted DNA was analysed for the presence of $W$. bancrofti DNA by qPCR using the method of Rao et al. [15]. In brief, the long DNA repeat (LDR) of W. bancrofti was targeted with specific forward and reverse primers (LDR1 and LDR2) and TaqMan probe for amplification and detection. In the reaction mixture, each $10 \mu \mathrm{l}$ of PCR consisted of $0.5 \mu \mathrm{M}$ of each of the two primers (LDR1 and LDR2), $12.5 \mu \mathrm{l}$ of TaqMan probe (Applied Biosystems, Foster City, CA, USA), 1:1 SensiMix ${ }^{\mathrm{mm}}$ (Bioline, Meridian Bioscience Asia Pte Ltd, Queenstown, Singapore) and $1 \mu \mathrm{l}$ of DNA extract. Thermal cycling conditions included $95^{\circ} \mathrm{C}$ for $10 \mathrm{~min}$ followed by 40 cycles of denaturation at $92{ }^{\circ} \mathrm{C}$ for $15 \mathrm{~s}$ and annealing at $60{ }^{\circ} \mathrm{C}$ for $60 \mathrm{~s}$. Each batch of samples was run with positive and negative controls. Thermal cycling and sample analysis were performed with Agilent MX 3005P qPCR systems, with MXPro software (5301 Stevens Creek Blvd, Santa Clara, CA 95051, USA).

\section{Data analysis}

Data were entered in Excel spreadsheets (Microsoft Corp., Redmond, WA, USA) and subsequently analyzed with SPSS version 20.0 (SPSS, Inc., Chicago, IL, USA). Blood test results for CFA and MF, the presence of hydrocele or elephantiasis, demographic characteristics, and MDA compliance were compared by using the Chi-square test and $P$-values $\leq 0.05$ were considered statistically significant. The lower and upper limits of the 95\% confidence interval for the prevalence of MF and CFA were calculated according to the method described by Newcombe [21]. For pool screening qPCR, the probability that any one mosquito in the pool was infected with $W$. bancrofti was estimated by pool-screen v2.0.2 software providing maximum likelihood estimates for infection rates as previously described [22].

\section{Results}

\section{LF prevalence and disease burden}

A total of 854 individuals above five years-old in five villages of Rufiji District were examined for CFA, MF, hydrocele and elephantiasis. The overall male to female ratio was 1.3 , and the mean age of the participants was 32.3 years (range of 10-79 years). Of 854 individuals screened for LF infection, 9 (1.1\%) and 1 (0.1\%) had CFA and MF, respectively (Table 2 ). Males were significantly more infected (CFA) than females $\left(\chi^{2}=3.921, d f=1, P=\right.$ 0.048 ). Of the 48 individuals found with the chronic clinical manifestation of LF, 23/481 (4.8\%) and 25/854 (2.9\%) had hydrocele and elephantiasis, respectively (Table 2). None of the individuals with hydrocele or elephantiasis were found to have MF or CFA.

\section{LF transmission indices}

A total of 3334 mosquitoes were caught using CDC light traps of which $69(2.1 \%)$ were identified as species of the Anopheles gambiae complex, 1054 (31.6\%) were Culex quinquefasciatus, and 2211 (66.3\%) were non-filarial vector species. In the laboratory, filarial mosquito vectors were dissected for parity, and 558 parous vectors were examined under microscopy for infection with W. bancrofti. None of the mosquitoes examined for infection was found to carry W. bancrofti larvae of any stage (Table 3 ).

A total of 5460 gravid $C x$. quinquefasciatus were collected outdoors using CDC gravid traps and dissected to separate head, thorax and abdomen. An aliquot of DNA from the head, thorax and abdomen of the $5460 C x$. quinquefasciatus was tested in pools of five mosquitoes (a total of 1092 pools) with qPCR. Of 1092 pools of $C x$. quinquefasciatus tested, five pools were positive for $W$. bancrofti DNA. Further analysis by pool screen (v2.0.2 software) gave an estimate that $0.1 \%$ of the tested mosquitoes were infected (Table 3). Further analysis of an aliquot of DNA from head segments of the infected pools revealed the absence of infective mosquitoes (i.e. mosquitoes harboring third-stage larvae of W. bancrofti).

\section{MDA compliance concerning LF infection status}

Of the 854 individuals interviewed, $82.4 \%$ reported having participated in at least one previous MDA round, while $70.6 \%$ participated in an MDA that was conducted in September 2014 (about seven months before the present study). Individuals who did not participate in any of the previous rounds of MDA were significantly more infected (CFA) compared with those with a recent history of participating in MDA $\left(\chi^{2}=8.723, d f=1, P=\right.$ $0.003)$. The proportion of males with hydrocele was significantly higher in individuals who did not swallow drugs in any MDA round while the prevalence of elephantiasis was not significantly different between these two groups of participants (Table 4).

\section{Discussion}

LF elimination activities based on annual MDA with a combination of ivermectin and albendazole have been 
Table 2 Prevalence of CFA, microfilariae and clinical manifestation of lymphatic filariasis infection by gender, age and village location in Rufiji District, southeastern Tanzania

\begin{tabular}{|c|c|c|c|c|c|}
\hline Characteristic & No. (\%) examined & $\begin{array}{l}\text { No. (\%) with CFA } \\
{[95 \% \mathrm{Cl}]}\end{array}$ & $\begin{array}{l}\text { No. (\%) with MF } \\
{[95 \% \mathrm{Cl}]}\end{array}$ & No. (\%) with hydrocele ${ }^{a}$ & No. (\%) with elephantiasis \\
\hline \multicolumn{6}{|l|}{ Gender } \\
\hline Male & $481(56.3)$ & $8(1.7)[0.8-3.2]$ & $1(0.2)[0.0-1.2]$ & $23(4.8)$ & $18(3.7)$ \\
\hline Female & $373(43.7)$ & $1(0.3)[0.1-1.5]$ & $0(0.0)[0.0-1.0]$ & - & $7(1.9)$ \\
\hline Total & 854 & $9(1.1)[0.6-2.0]$ & $1(0.1)[0.0-0.7]$ & $23(4.8)$ & $25(2.9)$ \\
\hline \multicolumn{6}{|l|}{ Age (years) } \\
\hline $5-14$ & $188(22.1)$ & $1(0.5)[0.1-3.0]$ & $0(0.0)[0.0-2.0]$ & $0(0.0)$ & $1(1.0)$ \\
\hline $15-34$ & 307 (35.9) & $4(1.3)[0.5-3.3]$ & $1(0.3)[0.1-1.8]$ & $8(4.7)$ & $13(7.8)$ \\
\hline$\geq 35$ & $359(42.0)$ & $4(1.1)[0.4-2.8]$ & $0(0.0)[0.0-1.1]$ & $15(7.0)$ & $11(5.2)$ \\
\hline Total & 854 & 9 (1.1) [0.6-2.0] & $1(0.1)[0.0-0.7]$ & $23(4.8)$ & $25(2.9)$ \\
\hline \multicolumn{6}{|l|}{ Village } \\
\hline Nyamisati & $213(24.9)$ & $0(0.0)[0.0-1.8]$ & $0(0.0)[0.0-1.8]$ & $7(4.1)$ & $5(2.3)$ \\
\hline Nyambili & $196(23.0)$ & $6(3.1)[1.4-6.5]$ & $1(0.5)[0.1-2.8]$ & $5(5.0)$ & $10(5.1)$ \\
\hline Nyanjati & $189(22.1)$ & $0(0.0)[0.0-2.0]$ & $0(0.0)[0.0-2.0]$ & $3(3.6)$ & $7(4.1)$ \\
\hline Bungu & $172(20.1)$ & $3(1.7)[0.6-5.0]$ & $0(0.0)[0.0-2.2]$ & $4(5.1)$ & $3(1.7)$ \\
\hline Mchukwi & $84(9.8)$ & $0(0.0)[0.0-4.4]$ & $0(0.0)[0.0-4.4]$ & $4(8.3)$ & $0(0.0)$ \\
\hline Total & 854 & $9(1.1)[0.6-2.0]$ & $1(0.1)[0.0-0.7]$ & $23(4.8)$ & $25(2.9)$ \\
\hline
\end{tabular}

anenominator included only males

ongoing in Tanzania for more than a decade. Thus, regular monitoring is essential to evaluate the progress and make informed decisions on when it is safe to stop MDA intervention. Studies on the impact of MDA on LF transmission and infection in areas implementing diethylcarbamazine (DEC) and albendazole regimes such as American Samoa, India, Egypt and Papua New Guinea, have documented good progress towards elimination [23-25]. In sub-Saharan Africa, many LF-endemic countries are co-endemic with onchocerciasis and thus ivermectin is used to avoid the potential DEC-induced side effects on onchocerciasis patients. Using a combination of ivermectin and albendazole MDA strategy, some West African countries are showing good progress toward elimination of LF [26, 27], and Togo has been declared to have achieved LF elimination target $[28,29]$. In northeastern Tanzania, the impact of MDA with this drug combination has shown a remarkable decline in LF infection and transmission [30]. The documented declining trend in LF transmission suggests the need to conduct a WHO-approved transmission assessment survey (TAS) to determine whether MDA can be stopped in endemic areas showing good progress.

The findings of this study have shown that after 12 rounds of ivermectin and albendazole MDA in the Rufiji District there has been a progressive decline in LF prevalence and transmission since the start of MDA intervention in 2002. Before the MDA intervention, the prevalence of CFA, MF, hydrocele and elephantiasis was $49 \%, 18 \%$, $12 \%$ and $4 \%$, respectively ( $\mathrm{MoH} 2000$, unpublished). In this study, no children tested positive for CFA in 2015 surveys (after 12 rounds of MDA). This shows a significant decline in CFA rates compared to our previous findings in the same study area in 2012 (after 9 MDA rounds), which showed CFA rate of $14.3 \%$ among pupils screened [31]. This decline in CFA suggests a substantial reduction in the acquisition of new infection in children from 2012 to 2014. The prevalence of MF and CFA recorded in the current study $(0.1 \%$ and $1.1 \%$, respectively) were below the WHO-recommended elimination thresholds of $1 \%$ (for MF) and 2\% (for CFA) [3]. Our findings on the decline of

Table 3 Filarial mosquito vectors caught and analyzed for infection and or/infectivity with W. bancrofti using microscopy and qPCR

\begin{tabular}{lllllll}
\hline Collection method & Vector collected & Parous vectors & Method of analysis & No. analyzed & No. infected (\%) & No. infective (\%) \\
\hline Light trap & $1123^{\mathrm{a}}$ & $558^{\mathrm{b}}$ & Microscopy & 558 & $0(0)$ & $0(0)$ \\
Gravid trap & 5460 & - & GPCR & $1092^{c}$ & $5(0.1)^{\mathrm{d}}$ & $0(0)$ \\
\hline
\end{tabular}

${ }^{a}$ Filarial vector composition: Anopheles gambiae complex $(n=69)$ and Culex quinquefasciatus $(n=1054)$

barous vectors: An. gambiae complex $(n=45)$ and Cx. quinquefasciatus $(n=513)$

'Pools of $5 \mathrm{Cx}$. quinquefasciatus each

${ }^{d}$ Infection rate (Pool Screen V2.0.2; Likelihood ratio method; 95\% Cl: 0.03-0.22\%) 
Table 4 Demographic characteristics of the study population and their reported drug uptake in relation to their LF infection status

\begin{tabular}{|c|c|c|c|c|c|c|c|}
\hline Characteristic & No. (\%) of total & No. (\%) with CFA & $\begin{array}{l}X^{2} \text {-value } \\
(P \text {-value })\end{array}$ & $\begin{array}{l}\text { No }(\%)^{a} \text { with } \\
\text { hydrocele }\end{array}$ & $\begin{array}{l}X^{2} \text {-value } \\
(P \text {-value })\end{array}$ & $\begin{array}{l}\text { No (\%) with } \\
\text { elephantiasis }\end{array}$ & $\begin{array}{l}X^{2} \text {-value } \\
(P \text {-value })\end{array}$ \\
\hline \multicolumn{8}{|c|}{ Gender $(n=854)$} \\
\hline Males & $481(56.3)$ & $8(1.6)$ & $3.921(0.048)$ & $23(4.8)$ & - & $18(3.7)$ & $2.573(0.109)$ \\
\hline Females & $373(43.7)$ & $1(0.3)$ & & & & $7(1.9)$ & \\
\hline \multicolumn{8}{|c|}{ Age groups in years $(n=854)$} \\
\hline$\leq 29$ & $450(52.7)$ & $4(0.9)$ & $0.248(0.618)$ & $5(2.0)$ & $8.723(0.003)$ & $13(2.9)$ & $0.005(0.944)$ \\
\hline$\geq 30$ & $404(47.3)$ & $5(1.2)$ & & $18(7.8)$ & & $12(3.0)$ & \\
\hline \multicolumn{8}{|c|}{ Reported drug uptake in previous MDAs $(n=854)$} \\
\hline Yes & $704(82.4)$ & $4(0.6)$ & $8.723(0.003)$ & $9(2.4)$ & $22.743(0.001)$ & $19(2.7)$ & $0.737(0.391)$ \\
\hline No & $150(17.6)$ & $5(3.3)$ & & $14(13.7)$ & & $6(4.0)$ & \\
\hline \multicolumn{8}{|c|}{ Reported drug uptake in 2014 MDA $(n=854)$} \\
\hline Yes & $603(70.6)$ & $6(1.0)$ & $0.068(0.794)$ & $8(2.5)$ & $10.243(0.001)$ & $16(2.7)$ & $0.542(0.462)$ \\
\hline No & 251 (29.4) & $3(1.2)$ & & $15(9.1)$ & & $9(3.6)$ & \\
\hline
\end{tabular}

a Denominator included only males: for age group $\leq 29$ and $\geq 30$ there were 249 and 232 males; drug uptake in any previous MDA, 379 males swallowed the drugs while 102 did not swallow the drugs; drug uptake in 2014 MDA, 316 males swallowed the drugs while 165 did not

LF infection and transmission due to MDA intervention corroborate those reported by Simonsen et al. [30] in northeastern Tanzania.

Detection of W. bancrofti infection in mosquito vectors is an essential aspect of monitoring LF transmission as it provides real-time information on the presence of local transmission [14]. CDC light and gravid traps have been considered efficient tools for the collection of filarial vectors in areas where Anopheles and Cx. quinquefasciatus are the primary vectors [32]. Important filarial mosquito vectors found elsewhere in Tanzania, such as the species of the An. gambiae complex, An. funestus group and $C x$. quinquefasciatus have also been reported in Rufiji District [33]. In this study, none of the dissected filarial vectors examined for infection ( $C x$. quinquefasciatus and $A n$. gambiae complex) were found to carry $W$. bancrofti larvae of any stage. Using qPCR with high throughput and precision, the probability of finding an infected mosquito in any of the analysed pools of gravid $C x$. quinquefasciatus was estimated at $0.1 \%$. Importantly in the transmission, none of the mosquitoes tested with qPCR was found to carry an infective stage of $W$. bancrofti. The fact that we did not identify any LF-infective vector by either qPCR or dissection suggests that local transmission is extremely low if occurring at all in the study areas.

The present study showed that the prevalence of hydrocele and elephantiasis was lower than that reported by the MOH before MDA (MoHSW 2000, unpublished), but the survey methods differed and a statistical comparison of prevalence in the two studies could not be made. In contrast, the proportion of individuals with elephantiasis in the present study was similar to that reported by Gasarasi et al. [34] who conducted a study in the same area in 2000.
Other studies conducted elsewhere have indicated a moderate to no reduction in the prevalence of lymphoedema after several rounds of MDA [35, 36]. Therefore, the observed low rate of hydrocele in this study might be explained by the ongoing hydrocelectomy intervention in the district.

Treatment coverage and compliance are crucial factors to observe when assessing the impact of MDA on LF transmission. For MDA strategy to be effective, sustained high treatment coverage is critical to reach the elimination target within a reasonable time-frame [37]. Moreover, empirical evidence suggested that endemic areas with high baseline infection levels will require higher treatment coverage and a more sustained MDA intervention [38]. However, it has been documented that attaining optimal drug uptake during MDA is a challenge in LF control programmes in most of the endemic areas [39-41]. In this study, the surveyed drug uptake was 70.6 and $82.4 \%$ for the last MDA round (September 2014, seven months before the present study) and participation in any previous MDA rounds, respectively. The surveyed MDA coverage in our study was at the recommended range of $60-70 \%$ drug uptake rates required for interruption of transmission [37]. Although drug uptake was found to be significantly lower in respondents with hydrocele, previous studies have reported a low prevalence of microfilaraemia in individuals with hydrocele and elephantiasis $[42,43]$.

Our study has recorded a progressive and substantial decline in LF prevalence in the study areas when compared to the baseline values before MDA and also to a more recent survey conducted in the same villages in 2012 [31]. In addition to the impact of MDA, the universal distribution of long-lasting insecticide-treated nets which 
was implemented in 2012 could contribute to the drastic decline in LF disease prevalence. Insecticide-treated nets distributed for malaria control have been shown to reduce LF prevalence in some settings [44-47].

Despite a substantial decline in LF in this study areas, a recommendation to stop MDA could not be made because the current study methods did not follow WHO-approved TAS. The design of the present study was adopted as a result of limited funding and time to implement an elaborated WHO-approved TAS protocol. Moreover, the direct statistical comparison between the baseline study in 2000 and the present study could not be made due to the unavailability of a detailed methodology for the baseline study. With these limitations, it is advisable that a formal TAS is conducted before MDA can be stopped the area.

\section{Conclusions}

Analysis of indices of LF infection in the human population and filarial mosquito vectors demonstrated a substantial decline in the prevalence of LF in the study areas when compared with baseline values before the start of elimination activities based on MDA. We recommend a formal TAS to be conducted in the study areas to make an informed decision on whether MDA can be stopped in Rufiji District.

\section{Abbreviations}

LF: Lymphatic filariasis; MDA: Mass drug administration; CFA: Circulating filarial antigens; ICT: Immunochromatographic test cards; qPCR: Quantitative real time polymerase chain reaction; TAS: Transmission assessment survey; WHO: World health organization; CDC: Centers for Disease Control and prevention; DNA: Deoxyribonucleic acid; GPELF: Global Programme to Eliminate Lymphatic Filariasis; NLFEP: National Lymphatic Filariasis Elimination Programme

\section{Acknowledgements}

The authors extend their gratitude to the residents of the study area for participating in the study. Maembe Mzee Maembe (deceased) and Justine Mkeni are thanked for their technical assistance in mosquito collection, identification and dissections. The authors wish to thank the district authorities for allowing researchers to conduct this study. We are also grateful to the members of the general community for participating in the surveys.

\section{Funding}

The study received financial support from the Special Programme for Research and Training in Tropical Diseases (TDR), co-sponsored by UNICEF, UNDP, the World Bank and WHO. The funding bodies had no role in the design, data collection, analysis and interpretation of data and in writing the manuscript.

\section{Availability of data and materials}

All relevant data supporting the conclusions of this article are included within the article.

\section{Authors' contributions}

Conceived and designed the study: CJ, BN, YAD, DT and MNM. Performed the field experiments: $C J, B N, L R, Y A D$ and $M B$. Supervised laboratory work: $L R$ and MB: Wrote the paper: $C J, B N, Y A D, L R, M B$ and MNM. All authors read and approved the final manuscript.

\section{Ethics approval and consent to participate}

The study was approved by Muhimbili University of Health and Allied Sciences Research Ethical Review Board as well as the WHO Ethics Review Committee. Before the fieldwork, permission to conduct the study was obtained from the District Executive Director for Rufiji. Members of the community were informed of the purpose of the study during the village meetings in order to obtain their cooperation. Before any examination, a written informed consent was obtained from all adults. For children below 15 years, their parents/guardians signed the informed the consent on their behalf. Before setting the CDC light and gravid traps, written informed consent was obtained from the heads of the households and individuals sleeping in the mosquito collection rooms were provided with long-lasting insecticide-treated nets (LLINs). Study participants who were positive for CFA or MF were treated with ivermectin $(150-200 \mathrm{mg} / \mathrm{kg})$ and albendazole (400 mg) as done during MDA.

\section{Consent for publication}

Not applicable.

\section{Competing interests}

The authors declare that they have no competing interests.

\section{Publisher's Note}

Springer Nature remains neutral with regard to jurisdictional claims in published maps and institutional affiliations.

\section{Author details}

'Department of Parasitology and Medical Entomology, Muhimbili University of Health and Allied Sciences, P. O. Box 65011, Dar es Salaam, Tanzania. ${ }^{2}$ Department of Women's and Children's Health International Maternal and Child Health (IMCH), Uppsala Universitet, Uppsala, Sweden. ${ }^{3}$ National Institute for Medical Research, P. O. Box 9653, Dar es Salaam, Tanzania. ${ }^{4}$ Liverpool School of Tropical Medicine, Liverpool, UK. ${ }^{5}$ European and Development Countries Clinical Trials Partnership, Cape Town, South Africa. ${ }^{6}$ WHO Regional Office for Africa, Brazzaville, Republic of the Congo.

Received: 22 March 2018 Accepted: 17 October 2018

Published online: 13 November 2018

\section{References}

1. Ottesen EA. The global programme to eliminate lymphatic filariasis. Trop Med Int Health. 2000;5:591-4.

2. $\mathrm{WHO}$. Preparing and implementing a national plan to eliminate lymphatic filariasis. Geneva: World Health Organization; 2000. WHO/CDS/CPE/CEE/2000.16.

3. WHO. Global programme to eliminate lymphatic filariasis: progress report 2000-2009 and strategic plan 2010-2020. Geneva: World Health Organization; 2010. WHO/HTM/NTD/PCT/2010.6.

4. Bockarie MJ, Pedersen EM, White GB, Michael E. Role of vector control in the global program to eliminate lymphatic filariasis. Annu Rev Entomol. 2009;54:469-87.

5. Simonsen PE, Fischer PU, Hoerauf A, Weil GJ. The Filariases. In: Farrar J, Hotez PJ, Junghanss T, Kang G, Lalloo D, White NJ, editors. Manson's Tropical Diseases. 23rd ed. London: Elsevier Saunders; 2014. p. 737-65.

6. Knight R, Molyneux D. Lymphatic filariasis. In: Warrell DA, Cox TM, Firth JD. Oxford Textbook of Medicine. Oxford: Oxford University Press; 2012. doi: https://doi.org/10.1093/med/978099204854.001.1.

7. Gyapong JO, Kumaraswami V, Biswas G, Ottesen EA. Treatment strategies underpinning the global programme to eliminate lymphatic filariasis. Expert Opin Pharmacother. 2005;6:179-200.

8. Molyneux DH. Filaria control and elimination: diagnostic, monitoring and surveillance needs. Trans R Soc Trop Med Hyg. 2009;103:338-41.

9. Michael E, Malecela MN, Zervos M, Kazura JW. Global eradication of lymphatic filariasis: the value of chronic disease control in parasite elimination programmes. PLoS One. 2008;3:e2936.

10. WHO. Global programme to eliminate lymphatic filariasis: annual report on lymphatic filariasis 2001. Geneva: World Health Organization; 2002 WHO/CDS/CPE/CEE/2002.28

11. Malecela MN, Lazarus W, Mwingira U, Mwakitalu E, Makene C, Kabali C, et al. Eliminating LF: a progress report from Tanzania. J Lymphol. 2009;4:10-2.

12. Malecela MN, Kilima P, Mackenzie CD. Implementation and management of lymphatic filariasis control and elimination programmes: the Tanzanian experience. 
In: Simonsen PE, Malecela MN, Michael E, Mackenzie CD, editors. Lymphatic Filariasis Research and Control in Eastern and Southern Africa. Copenhagen: DBL Centre for Health Research and Development; 2008. p. 112-23.

13. Chu BK, Deming M, Biritwum NK, Bougma WR, Dorkenoo AM, El-Setouhy M, et al. Transmission assessment surveys (TAS) to define endpoints for lymphatic filariasis mass drug administration: a multicenter evaluation. PLoS Negl Trop Dis. 2013;7:e2584.

14. Goodman DS, Orelus JN, Roberts JM, Lammie PJ, Streit TG. PCR and mosquito dissection as tools to monitor filarial infection levels following mass treatment. Filaria J. 2003;2:11.

15. Rao RU, Atkinson LJ, Ramzy RM, Helmy H, Farid HA, Bockarie MJ, et al. A real-time PCR-based assay for detection of Wuchereria bancrofti DNA in blood and mosquitoes. Am J Trop Med Hyg. 2006;74:826-32.

16. URT. Population and housing census 2012. Dar es Salaam: United Republic of Tanzania; 2013.

17. McMahon JE, Marshall TF, Vaughan JP, Abaru DE. Bancroftian filariasis: a comparison of microfilariae counting techniques using counting chamber, standard slide and membrane (nucleopore) filtration. Ann Trop Med Parasitol. 1979;73:457-64

18. Rwegoshora RT, Pedersen EM, Mukoko D, Meyrowitsch DW, Masese N, Malecela MN, et al. Bancroftian filariasis: patterns of vector abundance and transmission in two East African communities with different levels of endemicity. Ann Trop Med Parasitol. 2005;99:253-65.

19. Irish SR, Stevens WM, Derua YA, Walker T, Cameron MM. Comparison of methods for xenomonitoring in vectors of lymphatic filariasis in northeastern Tanzania. Am J Trop Med Hyg. 2015;93:983-9.

20. Livak KJ. Organization and mapping of a sequence on the Drosophila melanogaster $\mathrm{x}$ and $\mathrm{y}$ chromosomes that is transcribed during spermatogenesis. Genetics. 1984;107:611-34.

21. Newcombe RG. Two-sided confidence intervals for the single proportion: comparison of seven methods. Stat Med. 1998;17:857-72.

22. Katholi $C R$, ToeÂ L, Merriweather A, Unnasch TR. Determining the prevalence of Onchocerca volvulus infection in vector populations by polymerase chain reaction screening of pools of black flies. J Infect Dis. 1995; 172:1414-7.

23. Ramzy RM, El Setouhy M, Helmy H, Ahmed ES, Abd Elaziz KM, Farid H, et al. Effect of yearly mass drug administration with diethylcarbamazine and albendazole on bancroftian filariasis in Egypt: a comprehensive assessment. Lancet. 2006;367:992-9.

24. Weil GJ, Kastens W, Susapu M, Laney SJ, Williams S, King CL, et al. The impact of repeated rounds of mass drug administration with diethylcarbamazine plus albendazole on bancroftian filariasis in Papua New Guinea. PLoS Negl Trop Dis. 2008;2:e344.

25. Liang JL, King JD, Ichimori K, Handzel T, Pa'au M, Lammie PJ. Impact of five annual rounds of mass drug administration with diethylcarbamazine and albendazole on Wuchereria bancrofti infection in American Samoa. Am J Trop Med Hyg. 2008;78:924-8.

26. King JD, Eigege A, Umaru J, Jip N, Miri E, Jiya J, et al. Evidence for stopping mass drug administration for lymphatic filariasis in some, but not all local government areas of Plateau and Nasarawa States, Nigeria. Am J Trop Med Hyg. 2012;87:272-80.

27. Richards FO, Eigege A, Miri ES, Kal A, Umaru J, Pam D. Epidemiological and entomological evaluations after six years or more of mass drug administration for lymphatic filariasis elimination in Nigeria. PLoS Negl Trop Dis. 201 1;5:e1346.

28. Sodahlon YK, Dorkenoo AM, Morgah K, Nabiliou K, Agbo K, Miller R, et al. A success story: Togo is moving toward becoming the first sub-Saharan African nation to eliminate lymphatic filariasis through mass drug administration and countrywide morbidity alleviation. PLoS Negl Trop Dis. 2013:7:e2080.

29. Budge PJ, Dorkenoo AM, Sodahlon YK, Fasuyi OB, Mathieu E. Ongoing surveillance for lymphatic filariasis in Togo: assessment of alternatives and nationwide reassessment of transmission status. Am J Trop Med Hyg. 2014;90:89-95.

30. Simonsen PE, Derua YA, Magesa SM, Pedersen EM, Stensgaard A, Malecela MN, et al. Lymphatic filariasis control in Tanga Region, Tanzania: status after eight rounds of mass drug administration. Parasit Vectors. 2014;7:507.

31. Jones C, Ngasalla B, Derua YA, Tarimo D, Malecela MN. Lymphatic filariasis elimination efforts in Rufiji, southeastern Tanzania: decline in circulating filarial antigen prevalence in young school children after twelve rounds of mass drug administration and utilization of long-lasting insecticide-treated nets. Int J Infect Dis. 2017:61:38-43.
32. Derua YA, Rumisha SF, Batengana BM, Max DA, Stanley G, Kisinza WN, Mboera LG. Lymphatic filariasis transmission on Mafia Islands, Tanzania: evidence from xenomonitoring in mosquito vectors. PLoS Negl Trop Dis. 2017;11:e0005938.

33. Kigadye ESP, Nkwengulila G, Magesa SM, Abdulla S. Spatial variability in the density, distribution and vectorial capacity of anopheline species in Rufiji District, southeastern Tanzania. Tanzan J Health Res. 2011;13:112-8.

34. Gasarasi DB, Premji ZG, Mujinja PG, Mpembeni R. Acute adenolymphangitis due to bancroftian filariasis in Rufiji District, southeast Tanzania. Acta Trop. 2000;75:19-28.

35. Pani SP, Yuvaraj J, Vanamail P, Dhanda V, Michael E, Grenfell BT, et al. Episodic adenolymphangitis and lymphoedema in patients with bancroftian filariasis. Trans R Soc Trop Med Hyg. 1995;89:72-4.

36. Kazura JW, Bockarie MJ. Lymphatic filariasis in Papua New Guinea: interdisciplinary research on a national health problem. Trends Parasitol. 2003:19:260-3.

37. Michael E, Malecela-Lazaro MN, Simonsen PE, Pedersen EM, Barker G, Kumar A, et al. Mathematical modelling and the control of lymphatic filariasis. Lancet Infect Dis. 2004;4:223-34.

38. Michael E, Malecela-Lazaro MN, Kabali C, Snow LC, Kazura JW. Mathematical models and lymphatic filariasis control: endpoints and optimal interventions. Trends Parasitol. 2006;22:226-33.

39. Kisoka WJ, Simonsen PE, Malecela MN, Tersbøl PB, Mushi DL, Meyrowitsch DW. Factors influencing drug uptake during mass drug administration for control of lymphatic filariasis in rural and urban Tanzania. PLoS One. 2014;9:e109316

40. Babu BV, Mishra S. Mass drug administration under the programme to eliminate lymphatic filariasis in Orissa, India: a mixed-methods study to identify factors associated with compliance and non-compliance. Trans $\mathrm{R}$ Soc Trop Med Hyg. 2008;102:1207-13.

41. Gunawardena S, Ismail M, Bradley M, Karunaweera N. Factors influencing drug compliance in the mass drug administration programme against filariasis in the Western Province of Sri Lanka. Trans R Soc Trop Med Hyg. 2007:101:445-53.

42. Derua YA, Kisinza WN, Simonsen PE. Lymphatic filariasis control in Tanzania: infection, disease perceptions and drug uptake patterns in an endemic community after multiple rounds of mass drug administration. Parasit Vectors. 2018:11:429.

43. Dissanayake S. In Wuchereria bancrofti filariasis, asymptomatic microfilaraemia does not progress to amicrofilaraemic lymphatic disease. Int J Epidemiol. 2001;30:394-9.

44. Pedersen EM, Mukoko DA. Impact of insecticide-treated materials on filaria transmission by the various species of vector mosquito in Africa. Ann Trop Med Parasitol. 2002;96(Suppl. 2):S91-5.

45. Odermatt $P$, Leang $R$, Bin B, Bunkea $T$, Socheat $D$. Prevention of lymphatic filariasis with insecticide-treated bednets in Cambodia. Ann Trop Med Parasitol. 2008;102:135-42.

46. Njenga SM, Mwandawiro CS, Wamae CN, Mukoko DA, Omar AA, Shimada $M$, et al. Sustained reduction in prevalence of lymphatic filariasis infection despite missed rounds of mass drug administration in an area under mosquito nets for malaria control. Parasit Vectors. 2011;4:90.

47. Ashton RA, Kyabayinze DJ, Opio T, Auma A, Edwards T, Matwale G, et al. The impact of mass drug administration and long-lasting insecticidal net distribution on Wuchereria bancrofti infection in humans and mosquitoes: an observational study in northern Uganda. Parasit Vectors. 2011:4:134.

Ready to submit your research? Choose BMC and benefit from:

- fast, convenient online submission

- thorough peer review by experienced researchers in your field

- rapid publication on acceptance

- support for research data, including large and complex data types

- gold Open Access which fosters wider collaboration and increased citations

- maximum visibility for your research: over $100 \mathrm{M}$ website views per year

At $\mathrm{BMC}$, research is always in progress.

Learn more biomedcentral.com/submission 